\title{
Ecofriendly bricks elaborated from coal waste of Moroccan Jerrada Mining
}

\author{
H. Ez-zaki ${ }^{1, *}$, A. Diouri ${ }^{1}$, A. Bouregba ${ }^{1}$, F. Amor ${ }^{1}$, S. Chhaiba ${ }^{1}$, O. Sassi ${ }^{2}$ and Y. El Rhaffari ${ }^{3}$ \\ ${ }^{1}$ Laboratoire de Chimie du Solide Appliquée, Mohammed V University, Rabat, Morocco \\ ${ }^{2}$ Laboratoire de Physico-Chimie des Matériaux, ENS, Mohammed V University, Rabat, Morocco \\ ${ }^{3}$ Equipe thermodynamique-Energétique, Centre d'Energie, Mohammed V University, Rabat, Morocco
}

\begin{abstract}
Solid waste generated during mining is one of the major environmental problems associated with this industrial activity. The best solution to overcome the environmental impact of this waste is to find recycling facilities in mass-produced products that can absorb the large quantities of these available byproducts. The present study shows the feasibility of using the coal waste of Moroccan Jerrada mining in the production of ecological brick. The first step consists of consecutive stages of crushing, grinding and heating at $650^{\circ} \mathrm{C}$ of the coal waste with a small amount of lime in order to promote the reactive products of elaborated binders. The second step of the process consists of mixing treated coal waste with a small amount of marble dust, sand, gravel, and water, then pressed and dried at room temperature to manufacture a laboratory ecofriendly bricks. The mechanical strength and thermal conductivity are investigated.
\end{abstract}

\section{Introduction}

In many different parts of the world, coal mine waste rocks generated by coal mining (extraction and processing) affected and damaged the environment due to the huge amount, occupied area, and acid generation [1-7]. However, many researches were focused to increase environmental performance in the mining sector. The reduction, reuse, recycling, and treatment of mineral processing waste are progressively getting more research and development attention for their contribution to enhancing the durability of the mineral industry. Coal wastes are being considered for use in many fields such as filler in hot mix asphalt [8], sulfur recovery [9, 10], fabrication of soils [1] and, as the focus of this work, fabrication of eco-friendly bricks.

Bricks are a structural building and construction material that has been used around the world for a long time. Traditional and usual bricks are fabricated from clay with high-temperature firing or from ordinary Portland cement (OPC) concrete which contains high incorporated energy with a large amount of $\mathrm{CO} 2$ generated during production. In many areas of the world, there is already a deficiency of natural source material for the production of the conventional bricks. For environmental protection and sustainable development, extensive research concentrated on the use of different types of industrial waste materials with different methods [11]-[13] has been conducted on the production of bricks from waste material; therefore it became the ideal approach to reduce wastes generation.
Jerada's mine coal production started in 1930 and stopped in 2003. It is located in the Northeast of Morocco. The production left behind large amounts of solid waste consisting mainly of gangue and other coal waste. Currently, twenty slagheaps and dumps of coal waste fill the urban space of Jerada, the largest conical in shape with a base of $450 \times 412 \mathrm{~m}$ and a height of $70 \mathrm{~m}$ and composed of approximately 18 million tones of materials.

This coal waste accumulation poses environmental and economic problems and has become sources of contamination of the soil, water and air [10-14]. The oxidation of sulphuric minerals (pyrite), the danger of draining and leaching is available, creates high concentrations of sulfates in the groundwater and harmful oxides. The presence of high concentration of sulfates in the groundwater is caused by oxidation of pyrite present in these wastes [15].

A suitable way of reducing the accumulation of large amounts of coal waste is the valorisation of these products, which eventually helps to solve urban planning problems, as well as avoiding as possible the environmental impact. In the other hand, coal waste is constituted by a mineral part which is extremely important to reuse them in the construction materials [16].

The aim of this work is to propose a brief procedure to produce ecofriendly bricks from coal gangue based on the mineral processing. The point was to give a useful destination for the huge amounts of coal materials generated from coal processing operations and, 
simultaneously, to create an appropriate material that enables to use in fabrication of construction materials, also to minimize the environmental impact by absorbing a large amount of coal waste.

\section{Materials and methods}

\subsection{Materials}

The coal waste (CW) sample is a mixture of representative soil samples collected from different places on the embankment of Jerada's mine dumps. The $\mathrm{CW}$ was grinded under $45 \mu \mathrm{m}$, and then characterized by XRF, XRD and DSC/TG. The X-ray fluorescence is a spectrophotometer Philips PW1404 X-Ray tube Sc/Mo LIF200 and the working conditions were $40 \mathrm{KV}$ and $70 \mathrm{~mA}$. Mineralogical characterization of the samples was carried out with Bruker D8 Advance model X-ray diffractometer. Differential Scanning Calorimetry analysis (DSC) and thermo-gravimetric analysis (TG) were executed using DSC/TG type SDTQ600 with a heating rate of $10^{\circ} \mathrm{C} / \mathrm{min}$ up to $1000^{\circ} \mathrm{C}$, and using $100 \mathrm{ml} / \mathrm{min}$ of dry air free of $\mathrm{CO}_{2}$ as carrier gas. The table 1 , figure 1 and figure 2 show the chemical composition, the $\mathrm{x}$-ray diffraction pattern and DSC/TG curve of $\mathrm{CW}$.

Table 1. Chemical composition (wt. \%) of coal waste.

\begin{tabular}{|ccccccc|}
\hline (wt.\%) & $\mathrm{CaO}$ & $\mathrm{Al}_{2} \mathrm{O}_{3}$ & $\mathrm{SiO}_{2}$ & $\mathrm{Fe}_{2} \mathrm{O}_{3}$ & $\mathrm{SO}_{3}$ & $\mathrm{MgO}$ \\
\hline $\mathrm{CW}$ & 0,56 & 21,59 & 52,18 & 4,663 & 0,97 & 0,99 \\
\hline
\end{tabular}

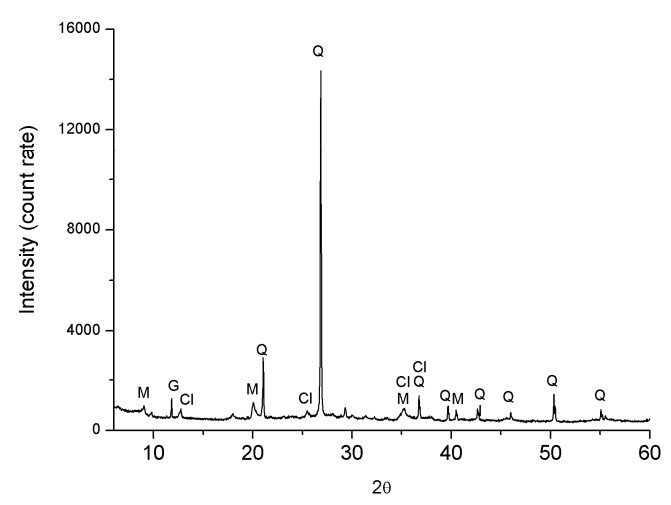

Fig.1. X-ray diffraction patterns for coal waste. $\mathrm{Q}=$ quartz; $\mathrm{M}=$ Muscovite; $\mathrm{G}=$ gypsum; $\mathrm{Cl}=$ Clinochlore .

We noticed that coal waste is composed mainly of silicon and aluminium oxides. The remaining compositions are iron, magnesium, sulphur and calcium oxides. The mineralogical analysis showed a large presence of quartz with muscovite, clinochlore and gypsum. In the temperature range $20-650^{\circ} \mathrm{C}$ (Figure 2 ), we notice two basic stages: the first endothermic region $\left(20-150^{\circ} \mathrm{C}\right)$ is attributed to the evaporation of free and bounded water; the second exothermic region $\left(450-650^{\circ} \mathrm{C}\right)$ is attributed to the combustion of the organic matter.

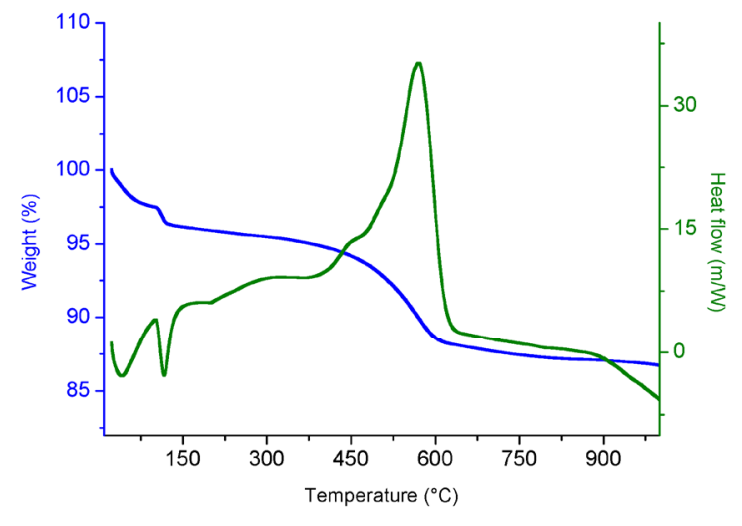

Fig. 2. DSC/TGA curve of coal waste under air atmosphereheating at $10^{\circ} \mathrm{C} / \mathrm{min}$.

\subsection{Methods}

\subsubsection{Elaboration of the binder}

The sample preparation protocol can be resumed as follow: The first step consists of consecutive stages of crushing, grinding and heating at $650^{\circ} \mathrm{C}$ of the coal waste (CW) with a little amount of lime in order to advance the reactive products of elaborated binders. The second step of the process consists of mixing treated coal waste (TCW) with a small amount of marble dust, sand, gravel, and water, then pressed and dried at room temperature to manufacture a laboratory ecofriendly bricks. The mechanical strength and thermal conductivity are investigated.

In this study, we focused on heating coal waste (WC) at $650^{\circ} \mathrm{C}$ for 2 hours to obtain a blend TCW. The choice of this temperature is due to the conversion of clay menials and the remove of the organic matter [17]. Then, we mixed $70 \% \mathrm{TCW}$ with $15 \% \mathrm{CaO}$ in order to advance the reactive products and $15 \%$ marble dust as a filler addition. The table 2 shows the proportion of the binder composition.

Table 2. Proportion of elaborated binder.

\begin{tabular}{|cccc|}
\hline (wt. \%) & TCW & $\mathrm{CaO}$ & Marble dust \\
\hline Binder & 70 & 15 & 15 \\
\hline
\end{tabular}

\subsubsection{Test specimens}

The followed process describes the manufacture of two types of specimens. Cylindrical mortars $(7.5 \mathrm{~mm} \varnothing \times 16$ $\mathrm{mm})$ and parallelepiped blocks $(70 \times 70 \times 10 \mathrm{~mm})$ are designed based on elaborated binder and then compared to the commercial cement $\mathrm{CPj} 35$ samples. Different proportions of elaborated binder, sand $(<2 \mathrm{~mm})$ and gravel $(<4 \mathrm{~mm})$ are prepared as listed in table 3 . 
Table 3. Mixes realized to prepare specimens.

\begin{tabular}{|ccccc|}
\hline (wt. \%) & CPj35 & $\begin{array}{c}\text { Elaborated } \\
\text { binder }\end{array}$ & Sand & Gravel \\
\hline Mortars: & & & & \\
MCPj_20 & 20 & - & 80 & - \\
M4_20 & - & 20 & 80 & - \\
M4_30 & - & 30 & 70 & - \\
M4_40 & - & 40 & 60 & - \\
\hline Blocks: & & & & \\
B4_20 & 20 & - & 30 & 50 \\
B4_20 & - & 20 & 30 & 50 \\
B4_30 & - & 30 & 25 & 45 \\
\hline
\end{tabular}

The mixture were homogenized, mixed with adequate amount of water to desired consistency, and then pressed under $5 \mathrm{MPa}$ using a hydraulic press. The samples were dried at ambient temperature until the testing day. A wet spray of specimens was established after one day of drying to promote the hydration reaction of binders, which provides the samples with certain early mechanical strength to avoid the crack in the following tests [18].

After 7, 28 and 56 days of drying, mechanical strength were carried out on cylindrical mortars with DY.22 machine. The thermal properties were characterized after 6 months of drying using CT-meter device. The measurement is based on monitoring the temperature increase for a measurement time of 300 s using a ring sensor in which are associated a heating element with a temperature sensor. In order to provide an excellent thermal contact, the ring sensor which has a radius of $15 \mathrm{~mm}$ must imperatively be sandwiched between flat faces of two identical parallelepiped blocks.

\section{Results and discussion}

\subsection{Mechanical strength}

After each drying time, compressive strength was undertaken on the cylindrical specimens. The values reported in the results represent the average of three strength values. The results for compressive strength as function of curing time are given in figure 3 .

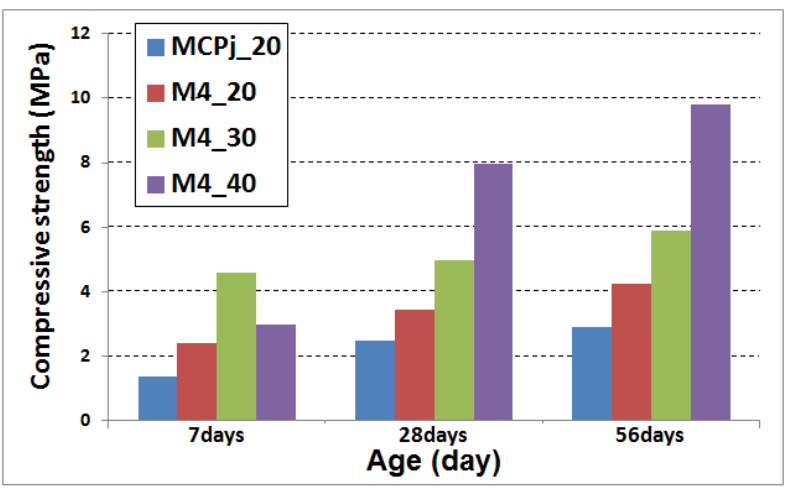

Fig. 3. Compressive strengths of different cylindrical specimens.

The compressive strength of binders was enhanced compared with the control (MCPj_20). It is observed that compressive strength has increased with the increase of binder content at all curing ages. The sample with $40 \%$ by weight of elaborated binder (M4_40) showed the highest compressive strength at almost all curing age. The increase in the strength of the samples with the increase of binder content may be assigned to the pozzolanic activity and the pore structure of the materials.

Studies have shown that the activated coal waste plays an important role in the pozzolanic activity. Activated coal waste showed a high pozzolanicity in which the kaolinite was converted into metakaolinite, and the presence of carbonate as reactive phases $[17,19,20]$. The metakaolinite favors the early pozzolanic activity; while calcium carbonate implies the adhesion between the aggregates and paste [21]. In the other hand, the finer particles of marble dust can involve a filler effect and play a noticeable role in the compressive strength [22]. A study showed that calcium carbonate in marble dust can provide sites for the nucleation and growth of hydration products that leads to further increase in strength [23].

\subsection{Thermal properties}

Thermal behaviour was investigated on parallelepiped specimens after 6 months of drying at ambient temperature. The thermal conductivity and volumetric heat capacity are presented in figure 4.

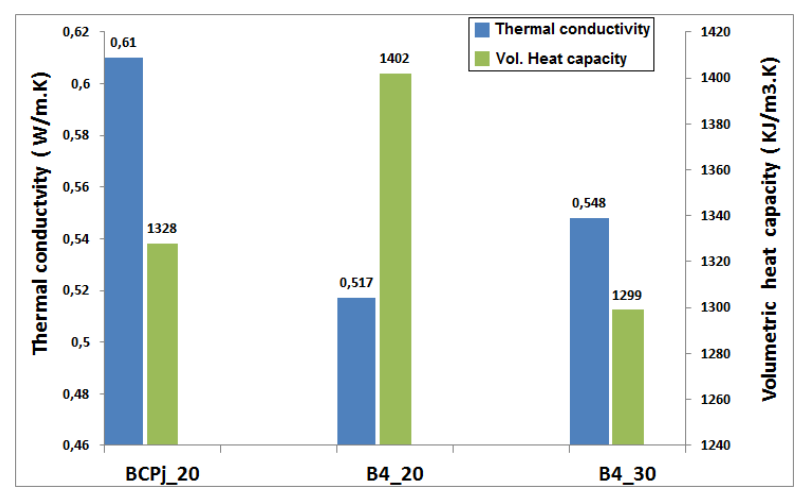

Fig. 4. Data of thermal conductivity and volumetric heat capacity of studied blocks.

As shown in figure 4 , the specimen with $20 \%$ of Portland cement has the high thermal conductivity which is 0.61 $\mathrm{W} / \mathrm{m} . \mathrm{K}$, compared to those of specimens with $20 \%$ and $30 \%$ of elaborated binder. The thermal conductivity increases from $0.517 \mathrm{~W} / \mathrm{m} . \mathrm{K}$ to $0.548 \mathrm{~W} / \mathrm{m} . \mathrm{K}$ for the shaped blocks with the increase of TCW binder from $20 \%$ to $30 \%$. With the increase of elaborated binder addition, the thermal conductivity increases. This may be due to the effect of studied materials.

In addition to the pozzolanic effect of TCW, the incorporation of marble dust can be considered as an effective way to reduce the porosity by the filler effect and improving the mechanical strength. However, the porosity behaves as a barrier to the flow of heat and leads to the decrease of thermal conductivity [24]. The use of high content of TCW and marble dust can cause a lower 
porosity and an increase in thermal conductivity of blocks. Some theoretical and experimental data showed that thermal conductivity of nanoporous materials decreases with increasing porosity [25]. Rahman et al [24] have reported that the increase of the petroleum coal dust addition conduct to the decrease of mechanical strength and thermal conductivity and the increase of porosity.

It can be seen that volumetric heat capacity of blocks with $20 \%$ of binder exhibits the highest value $(1402 \mathrm{~kJ} / \mathrm{m} 3 . \mathrm{K})$ compared to that of control and blocks with $30 \%$ of binder $\left(1328 \mathrm{~kJ} / \mathrm{m}^{3} . \mathrm{K}\right.$ and $1299 \mathrm{~kJ} / \mathrm{m}^{3} . \mathrm{K}$ respectively). The high value is considered as a desirable property due to the associated ability to store heat and it combines the specific heat capacity with material's density in which influenced by the content and the types of materials used [26, 27]. Therefore, it can be concluded that the use of a high content of elaborated binder can improve mechanical strength but at the same time deteriorate the thermal insulation of ecofriendly bricks. Thus, the main challenge is to find a balance between the desired thermal and mechanical properties.

\section{Conclusions}

In summary, coal waste can be used as the main raw material to overcome the environmental impact of this waste. This study showed one of the ways how coal waste as a solid waste can be feasible to produce ecological bricks.

The mixed treated coal waste and marble dust can increase the mechanical strength during curing time with increasing the amount of elaborated binder. The high mechanical strength of samples with high amount of this binder is attributed to the pozzolanic activity of treated coal waste and to the filler effect of marble dust which can improve the porous network and lead to the increase in strength. However, the increase of elaborated binder addition leads to the increase in thermal conductivity by reducing the porosity of materials. It can be explained by the behavior of porosity as a barrier to the flow of heat by storing it, whereof leads to a decrease in thermal conductivity.

Meanwhile, due to the increase in mechanical strength and the drop in thermal insulation by using a high amount of elaborated binder, the main challenge is to find a balance between the desired mechanical and thermal properties.

\section{References}

1. B.A. Firpo, J. R.D.A. Filho, I.A.H. Schneider, Minerals Engineering 76, (2015)

2. N. Gupta,V.V. Gedam, C. Moghe, P. Labhasetwar, Environmental Technology \& Innovation (2017)

3. D.M. Franks, D.V. Boger, C.M. Cote, D.R. Mulligan, Resources Policy 36, (2011)

4. L. Haibin, L. Zhenling, Conservation and Recycling 54, (2010)
5. H. Si, H. Bi, X. Li, C. Yang, International Journal of Coal Geology 81, (2010)

6. A.Yu. Stolboushkin, A.I. Ivanov, O.A. Fomina, Procedia Engineering 150, (2016)

7. D. van Beers, G.D. Corder, A. Bossilkov, R. van Berkel, Minerals Engineering 20, (2007)

8. A. Modarres, M. Rahmanzadeh, Construction and Building Materials 66, (2014)

9. C.K. Mbamba, S.T.L. Harrison, J.-P. Franzidis, J.L. Broadhurst, Minerals Engineering 29, (2012)

10. Y. Taha, M. Benzaazoua, R. Hakkou, M. Mansori, Miner. Eng. 107, (2017)

11. M. Sutcu, H. Alptekin, E. Erdogmus, Y. Er, and O. Gencel, Constr. Build. Mater. 82, (2015)

12. J. A. Calabria, W. L. Vasconcelos, and A. R. Boccaccini, Ceram. Int. 35, 2, (2009)

13. G. Cultrone and E. Sebastián, Constr. Build. Mater. 23, 2, (2009)

14. Y. Darmane, A. Alaoui, S. Kitane, M. Bennajah, A. Daramy, M. Cherkaoui, Sep. Purif. Technol. 68, 1, (2009)

15. B. Mounia, B. Mostapha, H. Rachid, B. Hassan, J. Abdelhakim, S. Mohamed, IJEST. 5, 8, (2013)

16. D. Belkheiri, A. Diouri, M. Taibi, O. Sassi, and J. Aride, J. Mater. Environ. Sci., 6, 6, (2015)

17. M. Frías, M.I. Sanchez de Rojas, R. García, A. Juan Valdés, C. Medina, Cement \& Concrete Composites 34, (2012)

18. J. Zhou, H. Gao, Z. Shu, Y. Wang, C. Yan, Construction and Building Materials 34, (2012)

19. Y. Li, Y. Yao, X. Liu, H. Sun, W. Ni, Fuel 109, (2013)

20. M. Frýas, R. Vigil de la Villa, MI. Sanchez de Rojas, C. Medina, A. Juan Valdes, J. Am. Ceram. Soc. 95, 1, (2012)

21. I. Vegas, M. Cano, I. Arribas, M. Frías, O. Rodríguez, Construction and Building Materials 99, (2015)

22. B. Demirel, International Journal of the Physical Sciences 5, 9, (2010)

23. Taner Kavas, Asim Olgum, Ceramics-Silikáty 52, 1, (2008)

24. M. H. Rahman, M.T. Islam, I.T. Minhaj, M.A.K. Azad, M.M. Hasan, A.A.M.R. Haque., Procedia Engineering 105, ( 2015 )

25. I. Sumirat, Y. Ando, S. Shimamura, J. Porous. Mater. 13, (2006)

26. H. Oktay, R. Yumrutas, A. Akpolat, Construction and Building Materials 96, (2015)

27. M. Pomianowski, P. Heiselberg, R.L. Jensen, Energy and Buildings 53, (2012) 